\title{
Effect of Hydro-Physical Properties of Peat on Regulation of Peatland Drainage Systems
}

\author{
Oleg Misnikov ${ }^{1, *}$ \\ ${ }^{1}$ Tver State Technical University, A. Nikitin Street, 22, 170026, Tver, Russia
}

\begin{abstract}
The paper analyzes changes in the hydro-physical properties of peat micro- and macrosystems in the process of drainage. Maximum moisture-holding capacity of peat is used as the main characteristic. With a full drying cycle and subsequent moistening of peat, there are three stages associated with the coagulative structure formation in the system. The boundary of the transition from the state «peat in water» to the state «water in peat» is moisture content equal to one. It divides the period of structure formation into two periods, due to the predominating action of van der Waals interactions or hydrogen bonds. In the state «water in pear» the peat system loses the ability to recover its original hydro-physical properties. Scaling up the research results on peat deposits (marshes) makes it possible to classify them according to the degree of drainage of the deposit. A new approach to the use of the term «surface water body» for peat deposits is proposed.
\end{abstract}

\section{Introduction}

An analysis of the information on hydrological features of peatlands is needed for their effective drainage. Such features are determined by geomorphology, the nature of water supply, types of vegetation, as well as conditions of internal and external moisture exchange in the deposits. The scientific substantiation of hydro-physical properties of peat is based on the classification of the types of moisture contact with the material [1]. The upper limit at which water is mechanically retained by peat is the relative humidity of 89 $90 \%$. Above these values, the moisture in the peatland is classified as free (not associated with the organic matter of peat). The boundary conditions may vary up or down in the medium range from 2 to $6 \%$. They are determined by the characteristics of the peat forming the deposit.

The water supply of the peatland depends on the conditions of its deposit and surface topography. The main goal of the drainage is to lower the groundwater level (GWL) of the peat deposit to a required rate. The rate depends on the further use of the deposit: peat harvesting, afforestation, agricultural use, etc. After the construction of the drainage system, the moisture content of the peat layer deposited above the GWL decreases by about $3-5 \%$. In its natural state, the moisture content of the peatland is rather high and mainly depends on the degree of decomposition of peat $\mathrm{R}_{\mathrm{P}}$ and the type of peat deposit (Table 1).

\footnotetext{
${ }^{*}$ Corresponding author: oleg.misnikov@gmail.com
} 
Table 1. Natural moisture content $w_{\mathrm{n}}(\%)$ of peat deposit in an undrained condition.

\begin{tabular}{|c|c|c|c|c|c|}
\hline \multirow{2}{*}{$\begin{array}{c}\text { Type of } \\
\text { deposit }\end{array}$} & \multicolumn{5}{|c|}{ Degree of decomposition $\mathbf{R}_{\mathbf{p}} \mathbf{\%}$} \\
\cline { 2 - 6 } & $\mathbf{1 0}$ & $\mathbf{2 0}$ & $\mathbf{3 0}$ & $\mathbf{4 0}$ & $\mathbf{5 0}$ \\
\hline Bog & 94.6 & 93.2 & 91.8 & 90.4 & 89.0 \\
\hline Fen & 93.0 & 91.0 & 89.0 & 87.0 & 85.0 \\
\hline
\end{tabular}

By calculating the moisture content of peat $W$, using a known moisture $w, \%$, it is possible to determine the mass of water $\left(m_{\mathrm{w}}\right)$ per unit mass of dry matter of peat (Table 2$)$, deposited in the peatland $\left(m_{\mathrm{d}}\right)$, using the formula: $W=m_{\mathrm{w}} / m_{\mathrm{d}}=w /(100-w)$. Thus, there is 5.7-17.5 more times of water mass than dry peat in the native peatland.

Table 2. Moisture content of peat deposits (in the undrained state) per unit mass of the dry matter of peat

\begin{tabular}{|c|c|c|c|c|c|}
\hline \multirow{2}{*}{$\begin{array}{l}\text { Type of } \\
\text { deposit }\end{array}$} & \multicolumn{5}{|c|}{ Degree of decomposition $\mathbf{R}_{\mathbf{p}}}$, \\
\cline { 2 - 6 } & $\mathbf{1 0}$ & $\mathbf{2 0}$ & $\mathbf{3 0}$ & $\mathbf{4 0}$ & $\mathbf{5 0}$ \\
\cline { 2 - 6 } moisture mass, kg \\
\hline Bog & 17.5 & 13.7 & 10.3 & 9.4 & 8.1 \\
\hline Fen & 13.3 & 10.1 & 8.1 & 6.7 & 5.7 \\
\hline
\end{tabular}

The main goal of drainage in relation to the technology of peat harvesting is to achieve a standard moisture content of the extracted layer of peat deposits. For example, during milled peat harvesting it should be equal to the indicators shown in Table 3.

During the harvesting of sod peat by the milling and molding method on the bog deposits, the slot-milling of peat deposits is carried out at the depth of up to $250 \mathrm{~mm}$ together with a simultaneous peat mass processing. After that, molding and spreading of sods is performed on the drying field. Table 4 demonstrates the values of the average moisture content of peat deposits by the milling depth, with an estimate of the amount of water to be removed when the swamp is drained from the natural $\left(w_{\mathrm{n}}\right)$ to operational $\left(w_{\mathrm{op}}\right)$ humidity.

Table 3. Humidity of exploited peat deposit layer during the harvesting of milled peat

\begin{tabular}{|c|c|c|c|c|}
\hline \multirow{2}{*}{ Year of exploitation } & \multicolumn{4}{|c|}{ Type of deposit } \\
\cline { 2 - 5 } & \multicolumn{3}{|c|}{$\begin{array}{c}\text { Bog, mixed and } \\
\text { transitional }\end{array}$} & \multicolumn{2}{c|}{ Fen } \\
\cline { 2 - 5 } & \multicolumn{4}{|c|}{ degree of decomposition } \\
\cline { 2 - 5 } & $<\mathbf{2 0} \%$ & $>\mathbf{2 0} \%$ & $<\mathbf{1 5} \%$ & $>\mathbf{1 5} \%$ \\
\hline First and second & 84 & 82 & 82 & 78 \\
\hline Third and following & 81 & 79 & 80 & 75 \\
\hline
\end{tabular}

Table 4. Humidity of the milled peat during the sod peat harvesting by the milling and molding method

\begin{tabular}{|c|c|c|}
\hline $\begin{array}{c}\text { Degree of } \\
\text { decomposition, } \\
\mathbf{\%}\end{array}$ & $\begin{array}{c}\text { Operational } \\
\text { moisture content } \\
\boldsymbol{w}_{\mathbf{~ o p}} \boldsymbol{\%}\end{array}$ & $\begin{array}{c}\text { The average weight (kg) of water } \\
\text { from } \boldsymbol{w}_{\mathbf{n}} \text { to } \boldsymbol{w}_{\text {op }} \text { removed during } \\
\text { draining per } \mathbf{~} \mathbf{~ k g} \text { of dry peat }\end{array}$ \\
\hline $20 \ldots 24$ & 82 & 8.0 \\
\hline $25 \ldots 29$ & 81 & 6.9 \\
\hline 30 and more & 80 & 5.4 \\
\hline
\end{tabular}

During the melioration of bogs with a low decomposition degree of peat, the requirements for drainage conditions are particularly stringent. They are due to the large water absorption capacity of the upper layers, in which, even with a relatively low level of groundwater, a significant amount of moisture is retained. Moreover, the low values of the 
coefficient of permeability hinder the infiltration of rainwater. In technological applications the following values are adopted [3]: $H_{\mathrm{gr}} \geq 0,8 \ldots 0,9 \mathrm{~m}$ (for fen deposits) and $H_{\mathrm{gr}} \geq 1 \mathrm{~m}$ (for bog deposits).

Thus, in the natural conditions of peatlands it is more correct to use the term «peat in water» instead of «water in peat». Moreover, it is applicable even after drainage works on a peat deposit. And although a peat deposit in this state has a certain (sometimes even rather high) structural strength, this allows it to be classified as a «surface water body».

\section{Method used}

The study of the state of the peatland systems during their drainage in the whole range of moisture content is connected to a number of complex issues associated mainly with drying. Therefore, this paper proposes to conduct studies on model peat samples with subsequent scaling of the results on a macro-object (peat deposit).

The experiment involves two types of bog peat (with the most moisture-holding capacity compared to fen peat): cotton-grass-sphagnum with $\mathrm{R}_{\mathrm{p}}=25 \%$ and magellanicum peat with $\mathrm{R}_{\mathrm{p}}=20 \%$.

The value characterizing the ability of peat systems to absorb and retain moisture is an indicator of the total moisture capacity $W_{\mathrm{FW}}$. Quantitatively, it can be characterized by relative humidity, expressed in percentages (\%). However, the moisture content indicator is used more often - absolute humidity. It is expressed as the ratio of a kilogram of water to a kilogram of dry matter $(\mathrm{kg} / \mathrm{kg})$. The main task of the research was to analyze the change in the total moisture capacity from the current moisture content of the samples during their drying. For this purpose, a comprehensive research methodology was applied, which included the following procedure.

1. Additional mechanical processing of peat mass before the molding. It increases the specific surface area $S\left(\mathrm{~m}^{2} / \mathrm{kg}\right)$ of peat particles composing the sample. In the experiments, the specific surface area was determined by the method of wet-sieve analysis [4].

2. Molding of peat cylindrical samples with a diameter $d=30,40$ and $60 \mathrm{~mm}$ and length $1=$ $1,5 d$ carried out in a screw extruder at from 75 to $80 \%$ moisture range of peat mass.

3. Drying of the experiment samples at convective heat supply, relative air humidity $70 \%$, temperatures $20 \pm 5^{\circ} \mathrm{C}$ (free convection, «soft» mode) and $60 \pm 5^{\circ} \mathrm{C}$ (forced convection, «hard» mode).

4. Determination of the total moisture capacity of the samples with the decrease in their moisture content during the drying process.

5. Termination of the experiment when the samples reach balanced moisture content.

In addition, it was necessary to analyze the change in the physical and structuralmechanical parameters of organic and mineral systems throughout the drying process and compare them with previously obtained data [5-10].

\section{Results and Discussion}

The results of the experiment demonstrate (Figures 1 and 2) that the total moisture capacity depends on the structural changes associated with the dehydration of the material. The specific surface area of the peat particles in the samples (Figure 1) was $360\left(1,1^{\prime}\right), 460(2$, $\left.2^{\prime}\right)$ and $550\left(3,3^{\prime}\right) \mathrm{m}^{2} / \mathrm{kg}$. With the further moistening of the dried samples, the decrease in the total moisture capacity is observed. Moreover, this dependence is not linear which is supported by the research of other authors [11]. The graphs show a certain zone, until which the system almost completely restores its water-physical properties (total moisture content tends to maximum values). It is clearly seen in the graphs 1, 1' (Figure 1), i.e. in the 
samples with the lowest (in this experiment) degree of mechanical dispersion. The moisture content of the samples in this zone is in the range between about 4 to $2.7 \mathrm{~kg} / \mathrm{kg}$ which corresponds to the total moisture capacity of $10.5-9.8 \mathrm{~kg} / \mathrm{kg}$. With the further decrease of the humidity in the peat, the irreversible changes begin to occur, and the original values of the total moisture content can no longer be achieved. But they can be quite high with drying up to $W_{i} \sim 1 \mathrm{~kg} / \mathrm{kg}$. Moreover, with the increase in the degree of mechanical dispersion, the total moisture capacity decreases and the system becomes more dependent on the degree of dehydration (compare curves 1, 1' with curves 2, 2' and 3, 3' in Figure 1).

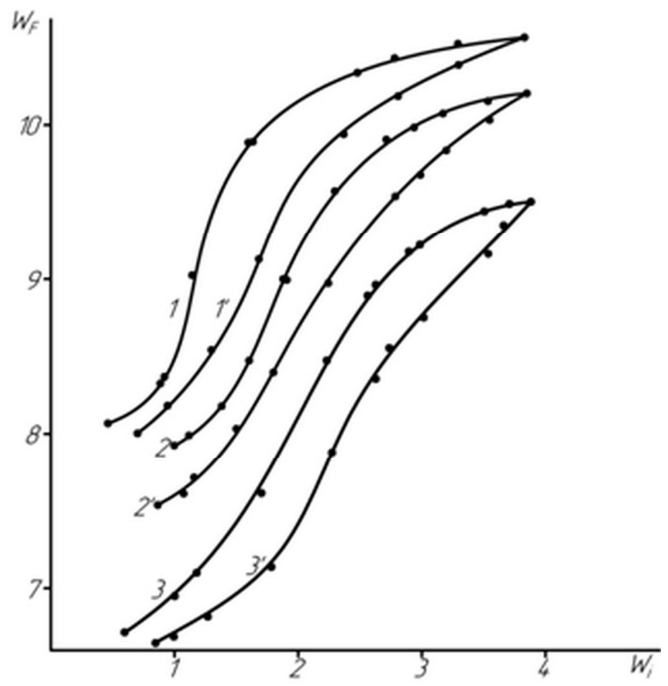

Fig. 1. Change of the total moisture capacity value $W_{\mathrm{F}}(\mathrm{kg} / \mathrm{kg})$ of the molded samples of bog cottongrass-sphagnum peat $\mathrm{R}_{\mathrm{p}}=25 \%$ with drying: in the «soft» $(1,2,3)$; «hard» $\left(1^{\prime}, 2^{\prime}, 3^{\prime}\right)$ modes (explanation is in the text).

Further on, let us analyze the reverse process - peat drying. It begins at a high initial humidity when the sample is in the swollen state. In this state, the cavities between macromolecules of organic matter of peat, their aggregates and associates are filled with moisture. Moreover, the process is further complicated by the fact that the aggregates and associates of organic (as opposed to mineral) peat matter are permeable to water molecules. That means that they have intra-associate and intra-aggregate moisture. When it is removed, shrinkage of peat (or settling of peat deposit) occurs, its density increases and its permeability decreases.

This hinders the movement of water molecules from the peat matrix to the evaporation zone. Therefore, there is a peculiar retention of them, which requires additional energy for the removal of moisture from peat. Due to the structural reorganization of the links of macromolecules of organic matter, the local sorption volume constantly changes (it decreases with the drying and increases with the moistening). The analysis of Figure 1 shows that the dehydration process begins to irreversibly change the structure of peat with the decrease in the moisture content to $2-1 \mathrm{~kg} / \mathrm{kg}$. 


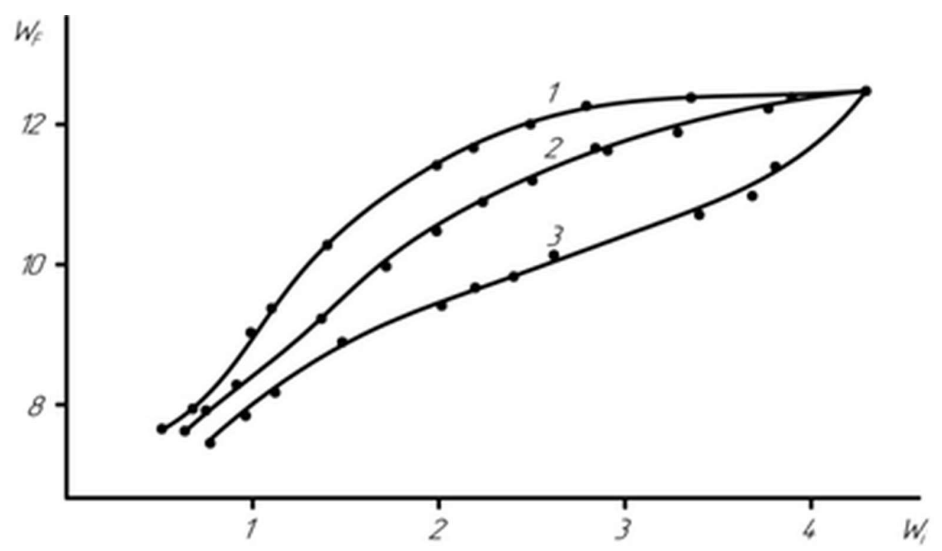

Fig. 2. Impact of the geometrical dimensions of the molded samples of magellanicum peat with $\mathrm{R}_{\mathrm{p}}=20 \%$ and $S=450 \mathrm{M}^{2} / \mathrm{kg}$ on the value of the total moisture content $W_{\mathrm{F}}(\mathrm{kg} / \mathrm{kg})$ with drying in the «soft» mode: $d=60$ (1), 40 (2), 30 (3) $\mathrm{mm}$

It is especially noticeable during the assessment of the drying mode impact. With a "harder" dehydration mode, the degree of change in the peat structure is higher. This is due to the lack of time for the flow of a potential (for these conditions) structure formation process and the full implementation of shrinkage stresses. Therefore, the subsequent relaxation of shrinkage stresses leads to increased cracking in the samples and, accordingly, to the violation of their integrity.

Also, the probability of irreversible processes in peat increases with decreasing sizes of peat samples (compare curve 1 with curves 2, 3 in Figure 2) during dehydration. This is explained by approximately the same mechanism that manifests itself in fine peat (reduction of the content of intra-associate and intra-aggregate moisture) [6,9].

When applied to the process of peat deposits drainage (a macro-object with undisturbed structure of peat deposits and an average specific surface area less than $100 \mathrm{~m}^{2} / \mathrm{kg}$ ) it means that the irreversible processes in the structure to moisture content $W=2-2.5 \mathrm{~kg} / \mathrm{kg}$ are unlikely.

In its natural state in the peatlands, groundwater is close to its surface and often comes onto the surface. Water-rich peat deposit has a very low bearing capacity. This makes it impossible to use peat harvesting equipment on it. Therefore, drainage should not only reduce the moisture content of the deposit, but also contribute to the creation of a flat and dense surface (Figure 3), ensuring a reliable ability of peat machines to perform on the peatland [2].

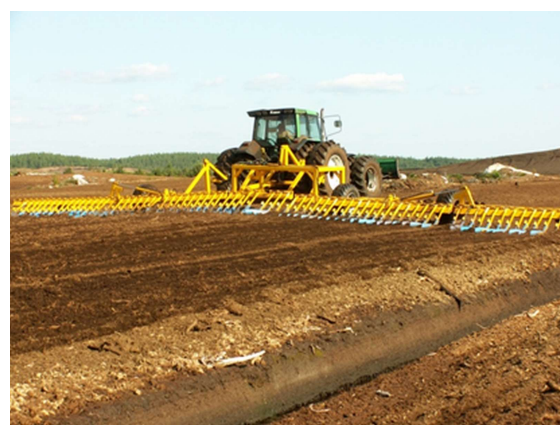

Fig. 3. Work process of a milled peat tedder on the drained peat deposit. 
The intensity of the peat drying process increases along with the increase in quality of drainage of the deposit. This is connected to the lowering of initial moisture content of the dried peat as well as to the decrease in moisture amount coming to the drying peat from inside the deposit $[9,10]$. An objective indicator of the degree of drainage of peat deposits is considered to be the position of the surface of free groundwater. With a short distance to the groundwater level, there is a significant replenishment of the upper layers of the drained deposit with moisture. This is due to the rise of water through capillaries, which increases their moisture content. Simultaneously, there is additional (though insignificant) removal of moisture due to its subsequent evaporation [10,11]. This approach is valid for the incompact peat deposits. If peat on this deposit is harvested, then multiple drives of technological equipment (up to 100-150 times per season on each map) will lead to additional compaction of the upper layers of the deposit (by 25-35\%). This reduces the diameter of the capillaries and, accordingly, increases the height of the rising capillary moisture. It was established experimentally that the height of the capillary rise can be increased by $20-40 \%$ [13].

The threshold when a peat (drying process) or peatland (drainage) system changes to the state "peat in water" is the moisture content $W=1 \mathrm{~kg} / \mathrm{kg}(w=50 \%)$. It was established earlier [8] that with the moisture content close to this value there are structural changes during the drying of both peat and sapropel systems. However, the presence of a larger amount of ash components complicates the process. The ash content of sapropels can reach $85 \%$. It is known that mineral impurities in sapropel deposits make up to $70 \%$ (in relation to the total ash content). Moreover, these are mineral substances that are weakly bound with the organic part and can be easily separated by simple physical methods.

The bound energy of moisture (moisture potential [7]) with organic and mineral components of peat and sapropels is not equal. The moisture potential in the organic materials is much higher than in the mineral ones (clay, loam, etc.). Additionally, it was established [8] that the total moisture capacity of sapropel mineral matter is approximately $0.5 \mathrm{~kg} / \mathrm{kg}$, while of the organic matter is about $12 \mathrm{~kg} / \mathrm{kg}$. Therefore, the significant part of water mass in the sapropels and peat is connected with the organic matter. Therefore, when studying the processes of dehydration and structure formation in organo-mineral systems, it is more correct to analyze not the moisture content of the entire material, but only the moisture content of its organic component $\left(W_{\mathrm{o}}\right)$. The organic matter determines the waterphysical properties of the entire system as a whole. The moisture content of the same mineral components of the organic material can be neglected.

In this case, using the known moisture content of the material, it is necessary to calculate the mass of water and dry matter. Then - determine the mass of organic $m_{\mathrm{o}}$ and mineral $m_{\mathrm{m}}$ components using the ash content indicator. The ratio of the mass of water $m_{\mathrm{w}}$ to the mass of organic matter $m_{\mathrm{o}}$ is an indicator of the moisture content of organic matter $W_{\mathrm{o}}$ in peat or sapropel $\left(W_{\mathrm{o}}=m_{\mathrm{w}} / m_{\mathrm{o}}\right)$. This approach is applicable to high-ash peat, peat soil, artificial organic-mineral mixture, etc.

By determining the estimated moisture content of the organic matter in the material and compare it with the total moisture content of the organic material, we can state that $W_{\mathrm{o}}>$ $W$.

This is most indicative during the transition of the organic (organo-mineral) systems from the first to the second period of structure formation (according to A.E. Afanasyev) [14]. The threshold of this transition is the point $W_{\mathrm{s}}$. For the peat of different types and kinds as well as for the organic sapropel this point equals to the moisture content of about one, $W_{\mathrm{s}} \approx 1 \mathrm{~kg} / \mathrm{kg}$. With increasing content of the mineral component in the system, for example, carbonate (ash content $\mathrm{A}=64 \%$ ) and silica sapropel $(\mathrm{A}=74 \%$ ), the threshold shifts towards decreasing moisture content $W_{\mathrm{s}}=0.35 \mathrm{~kg} / \mathrm{kg}$ and $W_{\mathrm{s}}=0.25 \mathrm{~kg} / \mathrm{kg}$, respectively [8]. 
However, if we recalculate the moisture content corresponding to these materials to the moisture content of organic matter $W_{\text {so }}$, the following values will be obtained: for carbonate sapropel $W_{\text {so }}=0.94 \mathrm{~kg} / \mathrm{kg}$, and for silica $W_{\text {so }}=0.97 \mathrm{~kg} / \mathrm{kg}$. The same patterns are manifested in peat, as well as in organic and mineral mixtures of peat (sapropel) with various mineral fillers. This is due to the fact that at this threshold there is a sudden change in structural parameters due to the new state of the system (transition from the first to the second period of structure formation). A number of researchers associate this with the beginning of the mass manifestation of hydrogen interaction between the macromolecules of the organic matter of the material $[7,8,14]$. But, as a rule, the traditional drainage of peatland does not achieve such humidity values. They can be partially achieved only during ameliorative drainage of peatlands (Figure 4) and peatlands for subsequent agricultural use. In this case, along with a decrease in moisture content to almost critical values [11], peat mineralization processes occur, which also reduces its water-absorbing characteristics.

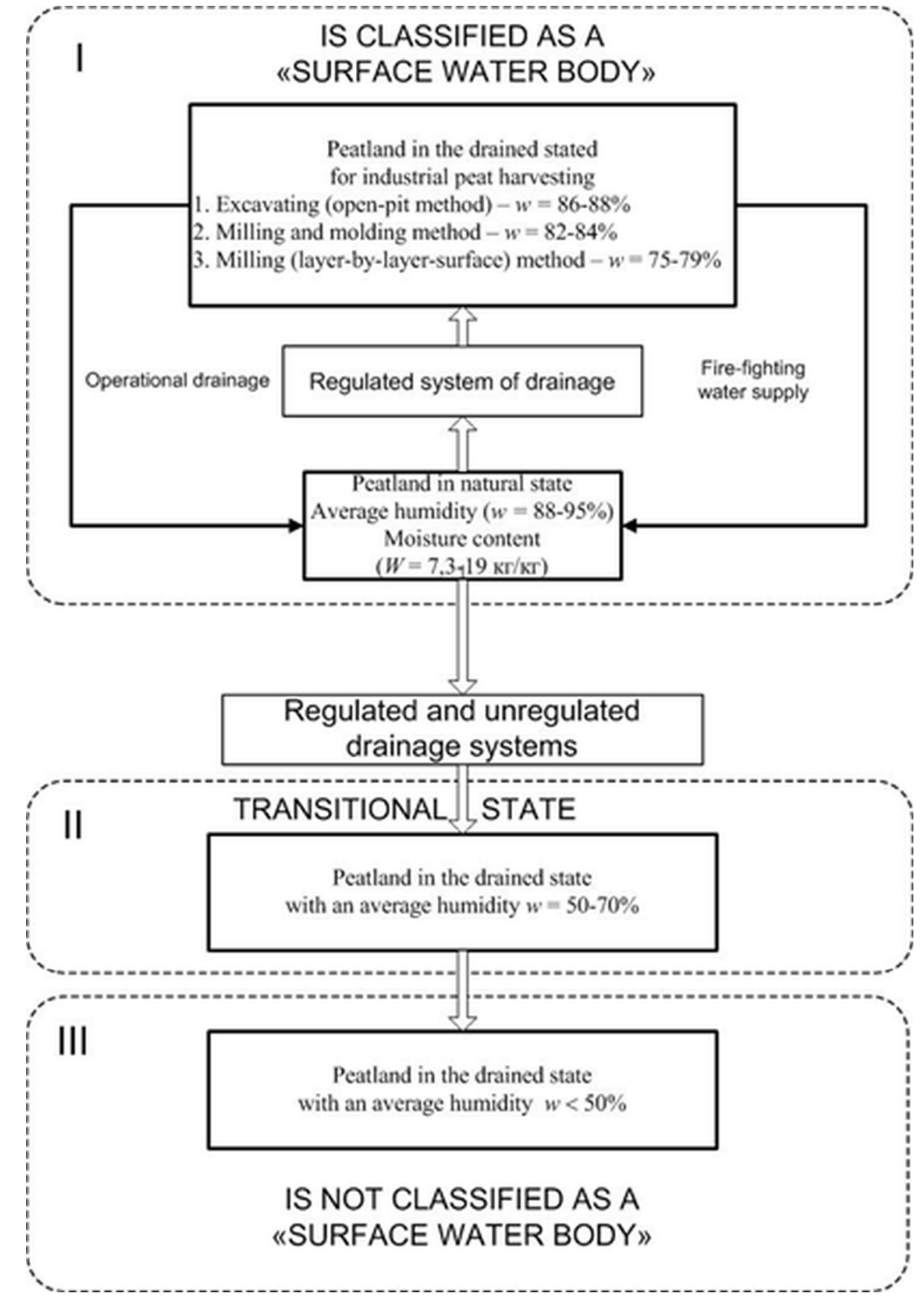

Fig. 4. Classification of peatlands on the degree of their drainage (explanation is in the text). 
Thus, the analysis of the water regulation process on the peatlands interconnected with the water-physical properties of peat deposits demonstrates that in its natural state a peatland is related to a surface water body.

It provides a constant or temporary concentration of water on the surface in the forms of its relief, which has boundaries, volume and features of the water regime. Moreover, the mass content of peat in it is on average from 5 to $12 \%$, i. e., 7.3-19 times less than the water content. The essential part of the water belongs to the category of free or mechanically associated with a binding energy of less than $1 \mathrm{~kJ} / \mathrm{mol}$.

A preliminary and operational drainage for the further peat harvesting decreases the average humidity in the exploited layer (operational humidity) of a peatland up to $75-88 \%$. However, in this case as well, the water content is 3-7 times higher than the peat content depending on the peat harvesting method used on this deposit.

Moreover, it is also weakly bound water of mechanical retention, the removal of which does not lead to significant structural changes in the deposit. It is necessary to stress once again that the average humidity in the exploited peatlands will be higher than operational. Humidity in the zone of the groundwater level during draining is not reduced. It will also be higher than operational in the zone of capillary rise. Therefore, after the inundation a peatland quickly restores its properties.

In this case, the systems of operational drainage and fire-fighting water supply (dualpurpose systems) quite quickly carry out (if necessary) the inundation of drained territories.

\section{Conclusions}

Thus, the research results can be the ground to classify peat deposits on which industrial peat extraction is carried out as surface water bodies (Position I, Figure 4). Regulated and unregulated drainage systems used for land amelioration can lower the deposit humidity below $50 \%$. In this case, the system changes from the «peat in water» state to the «water in peat» state, since their mass fractions are first equalized, and then the amount of water decreases. Additional aeration of the top layer of the drained peatland increases mineralization of the organic matter of peat and an even greater decrease in its waterabsorbing characteristics. With such values of moisture content, deep structural changes occur in the peat system. It will not reach previous water absorption capacity values during inundation. A peatland in such a state can no longer be classified as «surface water body» (Position III, Figure 4).

Drained peatlands with a humidity of $50-70 \%$ are in a transitional state (Position II, Figure 4). The mass of water slightly exceeds the mass of peat, but the processes of changing the natural water-physical characteristics are already beginning to appear in it. The use of various methods of moistening drained peatlands makes it possible to somewhat smooth out the effects of these processes. However, they cannot fundamentally change the situation, since the main tasks of moistening in peatlands drained for agricultural use are to create a favorable water-air regime for the root zone of plants. Such a regime will contribute to the mineralization of the top layer of the drained peatland.

In the case of restoration of water supply, within a certain period of time, the peatland formation process resumes on the object: the appearance of a free water surface, the growth and dying-off of peat-forming plants, etc. In the quantitative transition of the water mass relative to the mass of peat to over $50 \%$, it will also be possible to categorize such a peatland as a "surface water body". 


\section{References}

1. E. Kremcheev, D. Nagornov, Life Science Journal, 11:11, 453-456 (2014)

2. O. Misnikov, E3S Web Conf., 41, 01046 (2018)

3. L. Amaryan, E. Bazin, N. Churaev, Journal of Engineering Physics, 8:5, 436-438 (1967)

4. V. Lebedev, O. Puhova, E3S Web of Conf., 41, 01049 (2018)

5. A. Afanas'ev Colloid Journal of the Russian Academy of Sciences: Kolloidnyi Zhurnal, $\mathbf{5 3 : 3 , ~ 4 2 5 - 4 3 0 ~ ( 1 9 9 1 ) ~}$

6. A. Afanas'ev, A. Boltushkin, Colloid Journal of the Russian Academy of Sciences: Kolloidnyi Zhurnal, 58:2, 139-144 (1996)

7. A. Afanas'ev, S. Gamayunov, O. Misnikov, Colloid Journal, 61:3, 274-279 (1999)

8. A. Afanas'ev, O. Misnikov, Theoretical Foundations of Chemical Engineering, 37:6, 582-589 (2003)

9. N. Gamayunov, S. Gamayunov, Eurasian Soil Science, 38:3, 297-304 (2005)

10. N. Gamayunov, S. Gamayunov, Journal of Engineering Physics and Thermophysics, 77:1, 45-52 (2004)

11. E. Kremcheev, D. Nagornov, Ecology, Environment and Conservation, 23:2, 956-965 (2017)

12. E. Kremcheyev, D. Kremcheyeva, Indian Journal of Science and Technology, 9:12, 89525 (2016)

13. E. Kremcheev, D. Kremcheeva, Research Journal of Pharmaceutical, Biological and Chemical Sciences, 7:13, 1284-1289 (2016)

14. A. Afanas'ev, A. Efremov, Theoretical Foundations of Chemical Engineering, 45:1, 120-126 (2011) 